\title{
Uncertainty as a Key Influence in the Decision To Admit Patients with Transient Ischemic Attack
}

\author{
Barbara J. Homoya, RN, MSN" ${ }^{7,2}$, Teresa M. Damush, PhD ${ }^{1,2,3,4}$, Jason J. Sico, MD, MHS \\ Edward J. Miech, EdD ${ }^{1,2,3,4,7}$, Gregory W. Arling, PhD ${ }^{1,4,8}$, Laura J. Myers, $P h D^{1,2,3}$, \\ Jared B. Ferguson, BS ${ }^{1,2}$, Michael S. Phipps, MD', Eric M. Cheng, MD, MS ${ }^{10}$, and Dawn M. Bravata, \\ $M D^{1,2,3,4,11}$
}

\begin{abstract}
'Department of Veterans Affairs (VA) Health Services Research and Development (HSR\&D) Precision Monitoring to Transform Care (PRIS-M) Quality Enhancement Research Initiative (QUERI), Indianapolis, IN, USA; ${ }^{2}$ VA HSR\&D Center for Health Information and Communication (CHIC), Veteran Health Indiana, Indianapolis, IN, USA; ${ }^{3}$ Department of Internal Medicine, Indiana University School of Medicine, Indianapolis, IN, USA; ${ }^{4}$ Regenstrief Institute, Indianapolis, IN, USA; ${ }^{5}$ Clinical Epidemiology Research Center, VA Connecticut Healthcare System, West Haven, CT, USA; ${ }^{6}$ Departments of Internal Medicine and Neurology and Center for NeuroEpidemiological and Clinical Research, Yale School of Medicine, New Haven, CT, USA; ${ }^{7}$ Department of Emergency Medicine, Indiana University School of Medicine, Indianapolis, IN, USA; ${ }^{8}$ Purdue University School of Nursing, West Lafayette, IN, USA; ${ }^{\circ}$ Department of Neurology, University of Maryland School of Medicine, Baltimore, MD, USA; ${ }^{10}$ Department of Neurology, Los Angeles School of Medicine, University of California, Los Angeles, CA, USA; " Department of Neurology, Indiana University School of Medicine, Indianapolis, IN, USA.
\end{abstract}

BACKGROUND: Patients with transient ischemic attacks (TIA) are at high risk of subsequent vascular events. Hospitalization improves quality of care, yet admission rates for TIA patients vary considerably.

OBJECTIVES: We sought to identify factors associated with the decision to admit patents with TIA.

DESIGN: We conducted a secondary analysis of a prior study's data including semi-structured interviews, administrative data, and chart review.

PARTICIPANTS: We interviewed multidisciplinary clinical staff involved with TIA care. Administrative data included information for TIA patients in emergency departments or inpatient settings at VA medical centers (VAMCs) for fiscal years (FY) 2011 and 2014. Chart reviews were conducted on a subset of patients from 12 VAMCs in FY 2011.

APPROACH: For the qualitative data, we focused on interviewees' responses to the prompt: "Tell me what influences you in the decision to or not to admit TIA patients." We used administrative data to identify admission rates and chart review data to identify $\mathrm{ABCD}^{2}$ scores (a tool to classify stroke risk after TIA).

KEY RESULTS: Providers' decisions to admit TIA patients were related to uncertainty in several domains: lack of a facility TIA-specific policy, inconsistent use of $\mathrm{ABCD}^{2}$ score, and concerns about facilities' ability to complete a timely workup. There was a disconnect between staff perceptions about TIA admission and facility admission rates. According to chart review data, staff at facilities with higher admission rates in FY 2011 reported consistent reliance on $\mathrm{ABCD}^{2}$ scores and related guidelines in admission decision-making.

Prior Presentations These findings were presented at the International Stroke Conference in Houston, TX, in 2017.

Received February 14, 2018

Revised September 11, 2018

Accepted October 26, 2018

Published online November 27, 2018
CONCLUSIONS: Many factors contributed to decisions regarding admitting a patient with TIA; however, clinicians' uncertainty appeared to be a key driver. Further quality improvement interventions for TIA care should focus on facility adoption of TIA protocols to address uncertainty in TIA admission decision-making and to standardize timely evaluation of TIA patients and delivery of secondary prevention strategies.

KEY WORDS: transient ischemic attack; admission.

J Gen Intern Med 34(9):1715-23

DOI: $10.1007 / \mathrm{s} 11606-018-4735-9$

(c) Society of General Internal Medicine (This is a U.S. government work and not under copyright protection in the U.S.; foreign copyright protection may apply) 2018

\section{INTRODUCTION}

Patients with a transient ischemic attack (TIA) have a 3-10\% risk of stroke within 1 week of the event ${ }^{1,2}$ and an 8-17\% 90day stroke risk. ${ }^{1,3}$ In addition to stroke risk following TIA, patients have a $2.6 \%$ risk of cardiovascular events and $2.6 \%$ risk of death within 90 days. ${ }^{4}$ Based on a $25.1 \%$ overall shortterm recurrent vascular event rate, TIA patients should be considered as high risk for adverse events and their care should be delivered urgently and directed toward identification of index event etiology as well as risk factor management. The American Heart Association/American Stroke Association (AHA/ASA) ${ }^{5}$ and National Stroke Association (NSA) guidelines recommend urgent evaluation of TIA patients including admitting TIA patients if their workup cannot be completed in a timely fashion in the outpatient setting. ${ }^{6,7}$

Although hospitalization of TIA patients has been shown to improve the quality of TIA care, ${ }^{8-11}$ admission rates have been declining. A study from the US Nationwide Inpatient Sample (NIS) database demonstrated decreased hospitalization rates for 
TIA patients between 2000 and 2010 from 118 to 83 per 100,00 population. ${ }^{12}$ This reduction in hospital admissions for TIA may be due to: improved risk factor management resulting in a true reduced incidence; the revised definition of TIA in 2009, changing from a time-based definition to a tissue-based definition, thereby patients who would have been classified as TIAs under a time-based definition are now classified as strokes ${ }^{7}$; or new TIA management alternatives (e.g., TIA clinics, observation units) that obviate the need for hospital admission. ${ }^{12}$

Unlike acute stroke management, controversy exists regarding whether all TIA patients require care as inpatients because neurological symptoms have resolved. ${ }^{13}$ Many clinical and societal variables may contribute to the decision-making process regarding hospital admission ${ }^{14}$ and some clinicians advocate admission of all TIA patients. ${ }^{15}$ Rationale in support of universal hospital admission for TIA includes hospitalization allowing for timely evaluation, opportunity for intervention if a subsequent vascular event occurs, and rapid initiation of secondary prevention strategies. ${ }^{15,16}$ Opponents to universal TIA admission argue that alternatives such as urgent TIA clinics or observation units can provide care which is equivalent to inpatient services in terms of timeliness and quality but at a markedly reduced cost and potentially with enhanced patient convenience. ${ }^{17}$

Given these differences in opinion regarding whether or not to admit patients with TIA, it is not surprising that a high degree of variation exists in admission rates for patients with TIA. ${ }^{18}$ We sought to identify factors that were part of providers' decision-making process regarding admitting patients with TIA.

\section{METHODS}

We conducted a secondary analysis of a FY 2011 study from the Veterans Health Administration (VHA) which evaluated quality of care for Veterans with TIA and minor stroke. ${ }^{8,19,20}$ We included three sources of data: qualitative data from semi-structured interviews with facility staff members, administrative data, and medical chart review. Indiana University Institutional Review Board and Roudebush VAMC Research and Development Committee reviewed and approved this research.

\section{Qualitative Interview Data}

Interviews with stakeholders to evaluate TIA healthcare practices in the VHA were conducted in 2013-2014. ${ }^{20}$

Sites. Fourteen interview sites from diverse geographic regions (4 East, 4 Midwest, 2 Southwest, and 4 West) were chosen based on annual volume of $\geq 25$ patients with a TIA or minor stroke and willingness to participate in site visits. An adequate volume was needed to ensure sites' interest in TIA care processes, identify providers to interview who cared for patients with TIA on a regular basis, and plan for a future implementation project which would likely target sites which routinely cared for TIA patients. All 14 study sites had at least one neurologist on staff.

Participants. We interviewed clinical staff involved with TIA care from a broad range of disciplines including emergency medicine, neurology, hospitalist and medicine services, nursing, radiology, ophthalmology, primary care, quality management, cardiology, and pharmacy. The number of interviews per site ranged from 2 to 9 with an average of 5.3 interviews per site.

Data Collection. Our methods have been described elsewhere. ${ }^{20}$ Briefly, we interviewed participants about TIA processes of care - acute and follow-up - as well as facility characteristics, using a semi-structured interview guide. We obtained written permission to audiotape interviews. Audiotapes were professionally transcribed verbatim, de-identified, and imported into a single NVivo10 project file for data coding and analysis.

Data Analysis: Coding. For this secondary analysis, we focused on the interview question: "Tell me what influences you in the decision to or not to admit TIA patients." We compared information about influences on decision to admit across sites and among providers. From coded interviews, we identified emergent themes and patterns of factors cited by providers in their decision whether to admit TIA patients into inpatient care. We further categorized these factors as TIA clinical characteristics, patient perspectives, provider preferences, use of $\mathrm{ABCD}^{2}$ score, and uncertainty in three areas (diagnosis of TIA and risk of recurrence, resources, and practice). We illustrated these themes with quotations from respondents.

\section{Administrative Data}

Administrative data's purpose for the main study ${ }^{8}$ was to identify Veterans with TIA or minor stroke, develop electronic quality measure algorithms, and assess 90-day and 365-day outcomes, including death and recurrent events. Veterans with TIA or ischemic stroke who received care in FY 2011 and 2014 in any VHA Emergency Department (ED) or inpatient setting were identified (FY 2011, $n=$ 3676 with TIA; FY 2014, $n=3264$ with TIA). Final sample size for the administrative data cohort was $n=697$ (FY 2011) and $n=617$ (FY 2014) patients from the 14 interview sites. These data were used to identify the proportion of patients with TIA at each of the 14 sites who were directly admitted or admitted from the ED.

\section{Chart Review Data}

Chart review's primary purpose for the main study ${ }^{8}$ was to validate electronic process measure algorithms. We identified a random sample of patients from participating facilities by selecting a $35 \%$ random sample with a minimum of 25 patients per site. A total of $N=812$ chart reviews for patients with TIA or minor stroke was conducted at 39 different 
VAMCs for the main study. Chart reviews were performed at 12 of the 14 interview sites, but one site had no patients with TIA. Therefore, $\mathrm{ABCD}^{2}$ scores were from a random subset of patients with TIA from 11 sites, as the scores are only available from chart review.

Chart review at these 11 sites was used to obtain the $\mathrm{ABCD}^{2}$ score, a tool to identify risk of an ischemic stroke after TIA, based upon five criteria: age, blood pressure, clinical features, duration, and history of diabetes. ${ }^{4,21}$ Scoring ranges from 0 to 7; higher scores indicate higher risk of recurrent vascular events. Guidelines recommend admission based upon $\mathrm{ABCD}^{2}$ score (e.g., $\geq 3$ ) and other factors (inability to complete workup within $48 \mathrm{~h}$, focal findings). ${ }^{7}$

Analysis. Mean $\mathrm{ABCD}^{2}$ score was calculated at each facility for patients who were admitted and compared to those who were discharged from the ED. For each site, we compared providers' interview statements about use of the $\mathrm{ABCD}^{2}$ score in decision-making with the mean facility $\mathrm{ABCD}^{2}$ scores obtained from chart review data. We used $t$ tests to compare $\mathrm{ABCD}^{2}$ scores for patients who were admitted versus patients who were discharged from the ED.

\section{RESULTS}

We completed 70 interviews with clinical staff involved with TIA care at 14 facilities.

\section{Factors Influencing the Decision Whether To Admit}

TIA Characteristics. Characteristics of TIA events such as recent onset, presence of TIA symptoms while in the ED, or crescendo TIA were commonly cited by providers as reasons for admission. Providers also cited utilizing the $\mathrm{ABCD}^{2}$ score, which includes TIA clinical features (e.g., muscle weakness), as well as duration of symptoms. A delay in presentation (longer period since symptom onset), resolution of symptoms before or during ED stay, or a single TIA event (versus crescendo TIA) were reported as factors related to the decision not to admit:

If a patient's symptoms are already resolved, they are lower on the priority list. (Site A-Emergency Medicine)

Patient Perspectives About Admission. Clinicianinterviewees identified patient preference as a factor that influenced whether the patient was admitted; that is, providers reported that some patients did not want to be admitted because, for example, they "felt fine." Lack of availability of services sometimes resulted in Veterans refusing admission because of not wanting to wait over a weekend or holiday for testing to begin.
Some patients leave after being admitted, or instead of being admitted because they are asymptomatic, feel fine and have other things to do. This is especially true over the weekend, when some of the tests like echo and ultrasound are not available until Monday. (Site BNeurology)

Provider Preferences. Respondents cited their gestalt impression as influencing the decision whether to admit.

Admitting or not admitting a patient is more of a gut decision even after taking into consideration many of the health factors evaluated by the $\mathrm{ABCD}^{2}$ scale (age, diabetes, etc.). (Site A-Neurology)

Services such as availability of magnetic resonance imaging (MRI) and neurology consultation contributed to the decision not to admit both if they were lacking (as noted above) or if they were ample. Interviewees stated that when services were readily available, a workup could be completed from the ED and the patient did not need to be admitted Figure 1, Table 1 .

Availability of observation beds provided clinicians opportunity to monitor patients with TIA and conduct an expedited evaluation. Providers at facilities that had observation units cited this resource option in their decision not to admit patients.

Due to our new 10-bed clinical decision unit, which is located right next to the ED, we are able to admit TIA patients who were previously sent home after testing. (Site C-Emergency Medicine)

Another provider factor was a concern that patients who live a long distance from a VAMC would not be able to return for outpatient testing due to lack of transportation, financial means, or social support.

Our patient population tends to... have fewer resources in terms of family support, transportation, etc. (Site DNeurology)

However, proximity of the patient's residence to a VA facility and strong patient support at home contributed to providers' comfort with discharging a patient from the ED to home.

If a patient lives relatively close by and they had their TIA a week ago we probably wouldn't admit them. (Site D-Neurology)

Interviewees stated that they were more likely to not admit a TIA patient if the patient's medical management was already 


\section{Acute TIA Quality Processes of Care}

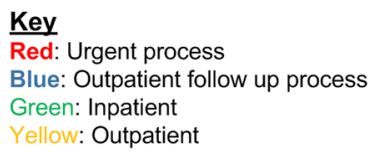

Key

Red: Urgent process

Blue: Outpatient follow up process

Green: Inpatient

Yellow: Outpatient
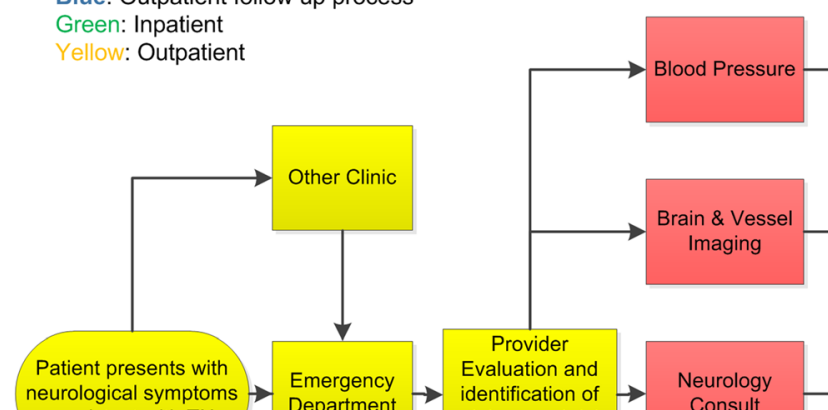

neurological symptoms $\rightarrow$ Eepartment

consistent with TIA
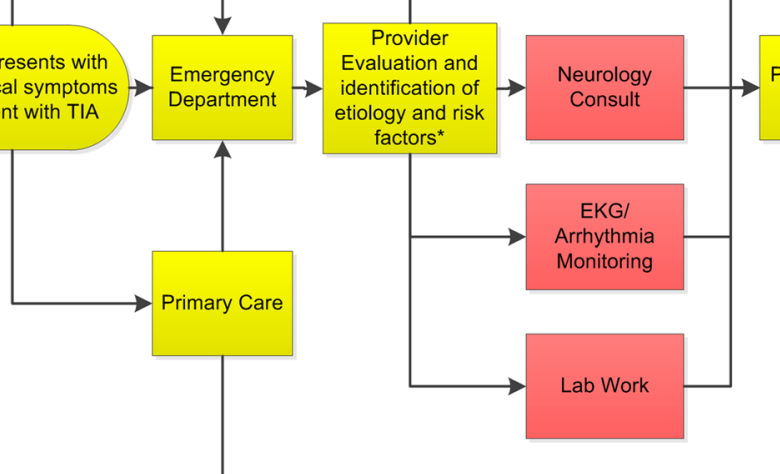

Note: * See Table 1

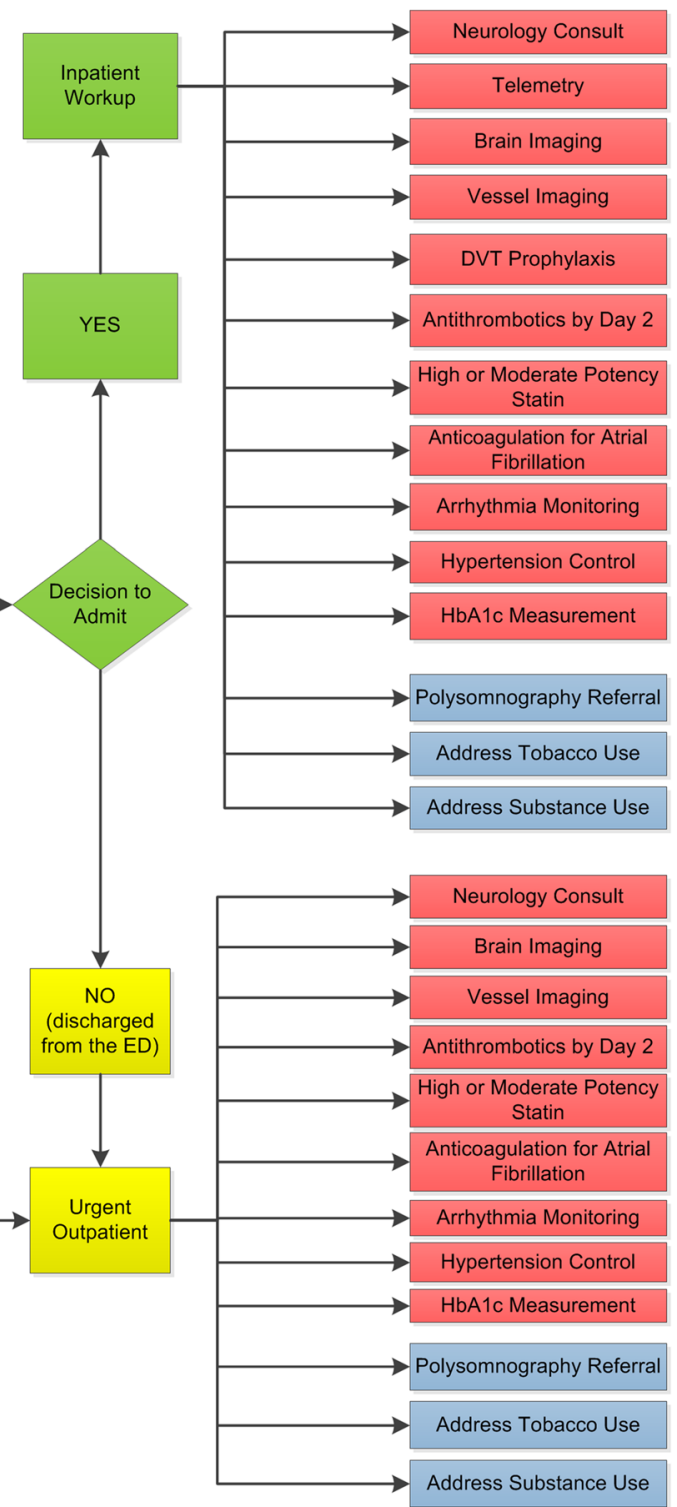

Figure 1 Acute TIA quality processes of care.

maximized or if the patient recently had an evaluation for a prior TIA or stroke event.

If...event was not very recent and they are on an excellent secondary prevention regimen...they will not be admitted. (Site E-Neurology)

$\boldsymbol{A} \boldsymbol{B C} \boldsymbol{C D}^{2}$. Respondents at five facilities reported that a high $\mathrm{ABCD}^{2}$ score was a driver of the decision to admit; a low $\mathrm{ABCD}^{2}$ score was reported by participants at six facilities as a factor in decisions not to admit.

Admittance is probably based upon $\mathrm{ABCD}^{2}$ score-very low percentile and a quick workup means that the patient may be sent home instead of admitted. (Site F-Neurology)

Diagnostic Uncertainty. In 2009, TIA's clinical definition was revised which may have contributed to increased diagnostic uncertainty. ${ }^{7,22}$ To be definitive, the diagnosis of TIA requires use of MRI, which is not always readily available. In addition, stroke mimics (e.g., migraine, nerve compression) add to uncertainty of diagnosis.

The ER doctors wouldn't want to send a TIA patient home and risk getting burned if it turns into a full-blown stroke a day later. (Site F-Hospitalist) 


\begin{tabular}{ll} 
& Table 1 TIA Risk Factors \\
\hline \hline Non-25 \\
\hline Age & Modifiable \\
Gender & Physical inactivity* \\
Race/ethnicity & Dyslipidemia* \\
Heredity/genetic & Diet and nutrition* \\
factors & Hypertension* \\
Low birth weight & Obesity and body fat distribution* \\
Socioeconomic & Diabetes mellitus* \\
Status & Cigarette smoking* \\
& Atrial fibrillation* \\
& Cardiac disease: CAD, CHF, \\
& LVH/cardiomyopathy, MI, MVP/valvular heart \\
& disease, PFO/ASA, cardiac tumors, aortic \\
& atherosclerosis* \\
& Asymptomatic carotid artery stenosis* \\
& Sickle cell disease* \\
& Migraine \\
& Metabolic syndrome \\
& Alcohol consumption \\
& Substance abuse (e.g., alcohol, cocaine) \\
& Obstructive sleep apnea \\
& Laboratory abnormalities: \\
& hyperhomocysteinemia, elevated Lp(a) \\
& Hypercoagulability \\
& Inflammation and infection \\
& Ocular fundi abnormalities \\
& Oral contraceptives \\
& Peripheral vascular disease \\
\hline
\end{tabular}

CAD coronary artery disease, CHF congestive heart failure, LVH left ventricular hypertrophy, MI myocardial infarction, MVP mitral valve prolapse, PFO patent foramen ovale, ASA atrial septal abnormalities

*Well-documented and modifiable risk factors

Resource Uncertainty. Staff reported uncertainty in their facility's ability to complete workups within 24 to $48 \mathrm{~h}$ in the outpatient setting, especially during weekends and holidays.

Discharging someone out of the ED for TIA would require figuring out how to get tests done within a very short period of time, which suggests to me that it's probably a lot easier to just admit them. (Site A-Hospitalist)

Practice Uncertainty. Uncertainty about local practice was cited as a factor by providers. Although VAMCs were required to develop a stroke care policy after the 2011 Treatment of Acute Ischemic Stroke VHA National Directive, TIA policy was not included. None of the interviewed providers reported that their facility had a policy guiding TIA care.

There is no standard policy for our facility and all clinicians have their own style. (Site F-Neurology)

\section{Belief That All TIA Patients Are Admitted}

Staff at 12 of the 14 facilities reported that they admitted all or most TIA patients, yet FY 2011 administrative data showed that 9 of 14 sites (64\%) admitted fewer than two thirds of TIA patients (Table 2). Facility TIA admission rates for FY 2011 ranged from 45.5 to $84.1 \%$ with a mean admission rate of $66.9 \%(\mathrm{SD}=47.1 \%$ ). For FY 2014, the range was slightly higher, 51.6 to $89.5 \%$. The facility with the lowest FY 2011 admission rate $(45.5 \%)$ was second highest $(87.5 \%)$ in FY 2014; in this case, the provider's perception would be in alignment with the more recent period. However, the highest facility admission rate in FY 2011 (84.1\%) was seventh highest (75.5\%) in FY 2014, in which case the provider's perception that all were admitted was less in alignment with the observed admission rate for the more recent year. Overall, the national rates were similar between the 2 years $(67.7 \%$ vs $72.2 \%$ ); nonetheless, there were differences at the individual facility level. Among facilities in this study, admission rates for TIA patients remained the same at five (36\%) facilities, were lower in FY 2014 at one (7\%) facility, and were higher at eight (57\%) facilities in FY 2014 compared to FY 2011. In both FY 2011 and FY 2014, providers at facilities with the lowest TIA admission rates reported that they admitted "all" or "most." Although the TIA admissions' rate increased for approximately two thirds of the facilities in FY 2014, none of the facilities admitted all of their TIA patients and nearly three quarters admitted less than $80 \%$.

In both years, perception by respondents that most TIA patients who presented to their facility's ED were admitted was inconsistent with the observed facility TIA admission rate.

TIAs all get admitted. (Site G-Emergency Medicine)

\section{Use of $A B C D^{2}$ Score}

Table 3 illustrates providers' use of the $\mathrm{ABCD}^{2}$ score from $\mathrm{FY}$ 2011 to guide admission decisions. Sites with higher admission rates reported greater reliance on use of the $\mathrm{ABCD}^{2}$ score. One facility at which a staff member stated he used the $\mathrm{ABCD}^{2}$ score had a TIA admission rate of $78.9 \%$. Although staff at nine $(64 \%)$ facilities stated that they utilized the $\mathrm{ABCD}^{2}$ in the decision to admit, many of the statements included qualifying conjunctions (such as "but" or "although").

We use the $\mathrm{ABCD} 2$ score here sometimes, but not always. (Site H-Neurology)

As noted previously, the $\mathrm{ABCD}^{2}$ score was cited as supporting evidence in the decision not to admit. Specifically, clinicians appeared to use the low $\mathrm{ABCD}^{2}$ score to validate their decision to discharge ED patients when other factors were present. ${ }^{26}$

Other uses of the $\mathrm{ABCD}^{2}$ score have been reported, including for patient education about stroke risk. ${ }^{27}$

Some patients don't want to stay in the hospital despite neurologists telling them about their $\mathrm{ABCD}^{2}$ score. (Site A-Neurology) 
Table 2 Disconnect Between the Provider's Belief That All TIA Patients Are Admitted and the Observed Facility TIA Admission Rate

\begin{tabular}{|c|c|c|c|c|}
\hline \multicolumn{4}{|c|}{ Percentage of TIA patients who were admitted } & \multirow[t]{3}{*}{ Illustrative quotations } \\
\hline \multicolumn{2}{|l|}{ FY11 } & \multicolumn{2}{|l|}{ FY14 } & \\
\hline$n / N$ & $\%$ & $n / N$ & $\%$ & \\
\hline $37 / 54$ & 68.5 & $51 / 57$ & 89.5 & "Generally I think that they are identified in the ED and admitted." \\
\hline $5 / 11$ & 45.5 & $14 / 16$ & 87.5 & "I think we always admit them." \\
\hline $27 / 42$ & 64.3 & $51 / 59$ & 86.4 & "TIAs all get admitted." \\
\hline $32 / 45$ & 71.1 & $36 / 54$ & 81.8 & "If TIA is suspected in the ED, they will be admitted." \\
\hline $25 / 43$ & 58.1 & $15 / 19$ & 78.9 & $\begin{array}{l}\text { "...because most of our population is over the age of } 65 \text {, or have } \\
\text { other risk factors, they will be admitted." }\end{array}$ \\
\hline $75 / 95$ & 78.9 & $66 / 84$ & 78.6 & "The vast majority of TIA patients are admitted." \\
\hline $53 / 63$ & 84.1 & $40 / 53$ & 75.5 & $\begin{array}{l}\text { "We admit the majority of TIA patients, because the patient cannot get } \\
\text { the procedures done as an outpatient in a timely fashion." }\end{array}$ \\
\hline $42 / 66$ & 63.6 & $32 / 45$ & 71.1 & $\begin{array}{l}\text { "Discharging someone out of the ED would require figuring out how to } \\
\text { get tests done within a very short period of time ... it's probably a lot } \\
\text { easier to just admit them." }\end{array}$ \\
\hline $30 / 48$ & 62.5 & $24 / 34$ & 70.6 & $\begin{array}{l}\text { "With ED providers, emphasize that TIAs and strokes should be lumped } \\
\text { together priority-wise - the event should still be considered acute and the } \\
\text { patient should be admitted" }\end{array}$ \\
\hline $18 / 28$ & 64.3 & $31 / 45$ & 68.9 & "We err on the side of admitting..." \\
\hline $44 / 68$ & 64.7 & $32 / 64$ & 68.1 & [Respondents from this site did not discuss admitting all TIA patients.] \\
\hline $27 / 51$ & 52.9 & $27 / 40$ & 67.5 & "Most probably do get admitted." \\
\hline $28 / 39$ & 71.8 & $29 / 43$ & 67.4 & "General default is to admit a patient with TIA like symptoms." \\
\hline $23 / 44$ & 52.3 & $16 / 31$ & 51.6 & "Generally we admit if there's any sort of residual symptom just to be safe." \\
\hline
\end{tabular}

Eighty-two percent of facilities had a mean $\mathrm{ABCD}^{2}$ score $>$ 4; only one facility had a mean $\mathrm{ABCD}^{2}$ score less than 3 . Except for one site, there was no statistical difference in mean $\mathrm{ABCD}^{2}$ score among admitted versus not admitted patients, but sample sizes were small (Table 3 ). Mean $\mathrm{ABCD}^{2}$ scores for patients who were admitted (mean 4.3, standard deviation, 1.4) were not consistently higher than mean $\mathrm{ABCD}^{2}$ scores for patients who were discharged from the ED (mean 4.0, standard deviation 1.5; $p=0.2991$; Table 3).

\section{DISCUSSION}

Our study includes a multidisciplinary assessment of provider-reported considerations regarding the decision to admit TIA patients. Uncertainty in clinical diagnosis, ability of the facility to conduct timely workups, patient preferences as reported by providers, and facilities' lack of a TIA policy were all key drivers of the decision to either admit patients with TIA to the hospital or discharge them from the ED. These results are similar to a prior study which found that because no gold standard diagnostic test for TIA exists, uncertainty in the TIA diagnosis is present in all TIA studies. ${ }^{28}$ Uncertainty in the TIA diagnosis may lead providers to rely more heavily on their gestalt clinical impression, ${ }^{29} \mathrm{a}$ factor cited by providers in our study as an element of the admission decision-making process.

Although we identified several areas of uncertainties factoring into a provider's decision to admit a patient, somewhat paradoxically, we regularly heard that all patients with TIA get

Table 3 Use of $\mathrm{ABCD}^{2}$ Score in Decision Whether To Admit Patient with TIA

\begin{tabular}{|c|c|c|c|c|c|}
\hline \multirow{2}{*}{\multicolumn{2}{|c|}{$\begin{array}{l}\text { Proportion of } \\
\text { TIA patients who } \\
\text { were admitted* }\end{array}$}} & \multicolumn{3}{|c|}{ Mean $\mathrm{ABCD}^{2}$ score (FY 2011) } & \multirow[t]{3}{*}{ Themes } \\
\hline & & \multirow{2}{*}{$\begin{array}{l}\text { Admitted } \\
\text { Mean } 4.3 ; \text { standard } \\
\text { deviation } 1.4 \text { ) }\end{array}$} & \multirow{2}{*}{$\begin{array}{l}\text { Not admitted } \\
\text { (Mean } 4.0 ; \text { standard } \\
\text { deviation 1.5) }\end{array}$} & \multirow{2}{*}{$\frac{P \text { value }}{(0.2991)}$} & \\
\hline$n / N$ & $\%$ & & & & \\
\hline $23 / 44$ & 52.3 & $4.3(1.6)$ & $3.9(0.7)$ & 0.4622 & Inconsistent use of $\mathrm{ABCD}^{2}$ \\
\hline $27 / 51$ & 52.9 & $4.6(1.1)$ & $4.0(1.6)$ & 0.4308 & Use clinical judgment rather than $\mathrm{ABCD}^{2}$ \\
\hline $25 / 43$ & 58.1 & $3.8(1.9)$ & $3.8(1.0)$ & 0.9611 & Inconsistent use of $\mathrm{ABCD}^{2}$ \\
\hline $30 / 48$ & 62.5 & $4.1(1.4)$ & $3.7(2.0)$ & 0.6513 & Provider resistance to using $\mathrm{ABCD}^{2}$ \\
\hline $42 / 66$ & 63.6 & $4.5(1.4)$ & $5.4(1.5)$ & 0.2906 & Use $\mathrm{ABCD}^{2}$ \\
\hline $27 / 42$ & 64.3 & $3.2(1.9)$ & $1.7(0.6)$ & 0.0513 & No statements about $\mathrm{ABCD}^{2}$ score \\
\hline $44 / 68$ & 64.7 & $4.2(1.2)$ & $6.0(0)$ & 0.1669 & \\
\hline $37 / 54$ & 68.5 & $4.5(1.7)$ & $4.5(2.1)$ & 0.9735 & \\
\hline $28 / 39$ & 71.8 & $4.6(1.1)$ & $5.4(0.5)$ & 0.1460 & Use $A B C D^{2}$ \\
\hline $75 / 95$ & 78.9 & $4.4(1.3)$ & $2.0(0)$ & $<0.0001$ & Use $A B C D^{2}$ \\
\hline $53 / 63$ & 84.1 & $4.6(1.4)$ & $\mathrm{n} / \mathrm{a}$ & - & Use $\mathrm{ABCD}^{2}$ \\
\hline
\end{tabular}

*Chart reviews were conducted on 12 of the 14 sites where staff were interviewed. At one of the sites where chart reviews were conducted, no eligible TIA patients were included in the chart review and therefore no $A B C D^{2}$ scores are available at that site 
admitted. However, despite this repeated contention, we found a disconnect between what was reported by providers and actual admission patterns based on administrative data. Like findings from another study, ${ }^{30}$ providers in our study stated they admitted most or all TIA patients. Yet, when we examined the actual facility TIA admission rates, some facilities admitted only about half of their TIA patients in both FY 2011 and FY 2014. It is unclear whether participants were stating what they believed to be their facility's admission practice or if responses were influenced by a social-response bias. ${ }^{31}$ Potential reasons for a disconnect between providers' perspectives (to admit all TIA patients) and the observed facility TIA admission rate may include neurologists were only aware of patients for whom they cared and were not aware of patients who were discharged from the ED without neurology care and providers may have thought about their most recent TIA patient with a definitive diagnosis, rather than considering the full spectrum of TIA patients, including patients with "uncertain" or equivocal symptoms.

Overestimation of admission rates and descriptions of other details of TIA care could be influenced by recall bias because individual staff members care for a relatively small number of TIA patients per year. Low TIA patient volume may also contribute to uncertainty with new or unfamiliar situations.

Availability of alternative management options may influence provider decision-making regarding inpatient admission. Although urgent TIA clinics and ED observation units may be lower cost alternatives to hospital admission, these are not presently available in many areas of the USA. ${ }^{29,32}$ Providers may be more likely to admit patients if they have the option of placing a patient in observation status. ${ }^{30}$ In the absence of observation units or TIA clinics, providers may seek to obtain diagnostic tests in the ED; however, constraints on ED resources which may either be fixed (e.g., lack of MRI) or dynamic (e.g., during ED crowding) may increase the likelihood that a provider will admit a TIA patient. ${ }^{33}$ Although many TIA patients can be appropriately managed in alternative settings, multidisciplinary care and certain testing services (e.g., telemetry) that are available routinely in inpatient settings (and less so in outpatient settings) may be needed for patients with certain event etiologies (e.g., cardioembolic events) or those with a higher degree of comorbidity. ${ }^{14}$ Until that level of care is available routinely in outpatient settings, hospital admission will be the "gold standard" in the USA for providing timely TIA care. ${ }^{5}$

We found that the $\mathrm{ABCD}^{2}$ score was not a major factor in most providers' decisions to admit TIA patients. Opinions varied about this tool—some participants stated they did not find it useful and some cited concerns about the reliability or accuracy. These impressions are supported by existing literature suggesting that $\mathrm{ABCD}^{2}$ scores may not be accurately calculated by non-stroke specialists ${ }^{34}$ and that they may be less predictive of stroke risk than other patient characteristics. ${ }^{35}$ McKesson's 2014 InterQual ${ }^{36}$ TIA admission criteria were based on the $\mathrm{ABCD}^{2}$ score, outpatient workup availability within 2 days (computed tomography [CT] or MRI, carotid artery imaging, and cardiac echocardiogram), resolution of neurologic symptoms, and appropriate interventions. ${ }^{7}$ Application of these criteria for TIA admission did not appear to be consistent across sites, although, the VHA utilizes InterQual criteria for admission decision-making. ${ }^{36}$ Lack of a facility TIA-specific policy might have contributed to the inconsistent decision-making regarding hospital admission for TIA patients.

Strengths of this study included diversity of facilities and participants who were interviewed and availability of administrative and chart review data to complement qualitative data. The primary limitation of the study is that it was conducted in VAMCs; generalizability of findings to non-VA facilities may be limited. Although administrative data may contain errors in coding, we previously validated the administrative data against chart review for the purpose of identifying patients with TIA; among patients identified as having a TIA by VHA administrative data, $95.0 \%$ had a TIA by chart review, $4.1 \%$ had a minor stroke by chart review, and $0.9 \%$ had neither TIA nor minor stroke by chart review. ${ }^{19}$ The chart review data used in the current study were obtained from a random sample of patients per facility; not all patients at the study sites received a chart review. Interviews were conducted at one point in time (FY 2013-2014), so we are not able to identify trends over time or to draw causal relationships. Another limitation was that transcripts were not read by interviewees to confirm the accuracy of their statements.

Our results indicate that many factors contribute to the decision whether to admit a patient with TIA; however, a key factor is uncertainty due to lack of guidance at sites without a facility TIA-specific policy, as well as inconsistent use of the $\mathrm{ABCD}^{2}$ score, patient's relative lack of symptoms, limited resources, and concerns about the ability of the system to complete a timely workup. Further research and quality improvement interventions for TIA care should focus on facility adoption of a TIA protocol to address key elements of the admission decision-making process and to standardize both evaluation of TIA and delivery of secondary prevention strategies.

Acknowledgments: We appreciate the time and effort of the VA facility clinical providers, staff, and administrators, and VISN leaders across the VHA who participated in our interviews. We thank Lauren Murphy for her assistance with manuscript preparation and submission and figure preparation.

Corresponding Author: Barbara J. Homoya, RN, MSN; Department of Veterans Affairs (VA) Health Services Research and Development (HSR\&D) Precision Monitoring to Transform Care (PRIS-M) Quality Enhancement Research Initiative (QUERI), Indianapolis, IN, USA (e-mail: Barbara.Homoya@va.gov).

Funding This work was supported by the Department of Veterans Affairs (VA), Health Services Research \& Development Service (HSRD), Quality Enhancement Research Initiative (QUERI) Service Directed Project (SDP 12-178) and by the VA HSRD, Precision Monitoring to Transform Care (PRIS-M) Quality Enhancement Research Initiative (QUERI) (QUE 15-280). Dr. Sico is supported by a VA HSRD Career Development Award (HX001388-01A1). 
Support for VA/Centers for Medicare and Medicaid Service (CMS) data is provided by the VA Information Resource Center (SDR 02 237 and 98-004).

\section{Compliance with Ethical Standards:}

Conflict of Interest: The authors declare that they do not have a conflict of interest.

\section{REFERENCES}

1. Giles MF, Rothwell PM. Risk of stroke early after transient ischaemic attack: a systematic review and meta-analysis. Lancet Neurol. 2007;6(12): 1063-72. https://doi.org/10.1016/s1474-4422(07)70274-0.

2. Wu CM, McLaughlin K, Lorenzetti DL, Hill MD, Manns BJ, Ghali WA Early risk of stroke after transient ischemic attack: a systematic review and meta-analysis. Arch Intern Med. 2007;167(22):2417-22. https://doi. org/10.1001/archinte.167.22.2417.

3. Wang Y, Wang Y, Zhao X, Liu L, Wang D, Wang C, Wang C, Li H, Meng X, Cui L, Jia J, Dong Q, Xu A, Zeng J, Li Y, Wang Z, Xia H, Johnston SC. Clopidogrel with aspirin in acute minor stroke or transient ischemic attack. N Engl J Med. 2013;369(1):11-9. https://doi.org/10.1056/ NEJMoa1215340.

4. Johnston SC, Gress DR, Browner WS, Sidney S. Short-term prognosis after emergency department diagnosis of TIA. JAMA. 2000;284(22):2901-6.

5. Kelly AG, Rothwell PM. Evaluating patients with TIA: to hospitalize or not to hospitalize?. Neurology. 2011;77(24):2078-9. https://doi.org/10. 1212/WNL.0b013e31824004fe.

6. Johnston SC, Albers GW, Gorelick PB, Cumbler E, Klingman J, Ross MA, Briggs M, Carlton J, Sloan EP, Vaince U. National Stroke Association recommendations for systems of care for transient ischemic attack. Ann Neurol. 2011;69(5):872-7. https://doi.org/10.1002/ana. 22332.

7. Easton JD, Saver JL, Albers GW, Alberts MJ, Chaturvedi S, Feldmann E, Hatsukami TS, Higashida RT, Johnston SC, Kidwell CS, Lutsep HL, Miller E, Sacco RL. Definition and evaluation of transient ischemic attack: a scientific statement for healthcare professionals from the American Heart Association/American Stroke Association Stroke Council; Council on Cardiovascular Surgery and Anesthesia; Council on Cardiovascular Radiology and Intervention; Council on Cardiovascular Nursing; and the Interdisciplinary Council on Peripheral Vascular Disease. The American Academy of Neurology affirms the value of this statement as an educational tool for neurologists. Stroke. 2009;40(6):2276-93. https://doi.org/10.1161/ strokeaha. 108.192218.

8. Bravata DM, Myers LJ, Arling G, Miech EJ, Damush T, Sico JJ, Phipps MS, Zillich AJ, Yu Z, Reeves M, Williams LS, Johanning J, Chaturvedi S, Baye F, Ofner S, Austin C, Ferguson J, Graham GD, Rhude R, Kessler CS, Higgins DS Jr, Cheng E. Guality of care for veterans with transient ischemic attack and minor stroke. JAMA Neurol. 2018;75(4):419-27. https://doi.org/10.1001/jamaneurol.2017.4648.

9. Scholte op Reimer WJ, Dippel DW, Franke CL, van Oostenbrugge RJ, de Jong G, Hoeks S, Simoons ML. Quality of hospital and outpatient care after stroke or transient ischemic attack: insights from a stroke survey in the Netherlands. Stroke. 2006;37(7):1844-9. https://doi.org/ 10.1161/01.STR.0000226463.17988.a3.

10. Kehdi EE, Cordato DJ, Thomas PR, Beran RG, Cappelen-Smith C, Griffith NC, Hanna IY, McDougall AJ, Worthington JM, Hodgkinson SJ. Outcomes of patients with transient ischaemic attack after hospital admission or discharge from the emergency department. Med J Aust. 2008; 189(1):9-12.

11. Kapral MK, Hall R, Fang J, Austin PC, Silver FL, Gladstone DJ, Casaubon LK, Stamplecoski M, Tu JV. Association between hospitalization and care after transient ischemic attack or minor stroke. Neurology. 2016;86(17):1582-9. https://doi.org/10.1212/wnl. 0000000000002614 .

12. Ramirez L, Kim-Tenser MA, Sanossian N, Cen S, Wen G, He S, Mack WJ, Towfighi A. Trends in transient ischemic attack hospitalizations in the United States. J Am Heart Assoc. 2016;5(9). https://doi.org/10. 1161/jaha.116.004026.

13. Nguyen-Huynh MN, Johnston SC. Is hospitalization after TIA costeffective on the basis of treatment with tPA? Neurology. 2005;65(11):1799-801. https://doi.org/10.1212/01.wnl.0000187067. 93321.fa.
14. Griffiths D, Sturm J, Heard R, Reyneke E, Whyte S, Clarke T, O'Brien W, Crimmins D. Can lower risk patients presenting with transient ischaemic attack be safely managed as outpatients?. J Clin Neurosci. 2014;21(1):47-50. https://doi.org/10.1016/j.jocn.2013. 02.028.

15. Cucchiara BL, Kasner SE. All patients should be admitted to the hospital after a transient ischemic attack. Stroke. 2012;43(5):1446-7. https://doi.org/10.1161/strokeaha.111.636746.

16. Rahiman A, Saver JL, Porter V, Buxton W, McNair N, Razinia T, Ovbiagele B. In-hospital initiation of secondary prevention is associated with improved vascular outcomes at 3 months. J Stroke Cerebrovasc Dis. 2008;17(1):5-8. https://doi.org/10.1016/j.jstrokecerebrovasdis.2007. 09.004.

17. Mijalski C, Silver B. TIA Management: should tia patients be admitted? Should TIA patients get combination antiplatelet therapy?. Neurohospitalist. 2015;5(3):151-60. https://doi.org/10.1177/1941874415580598.

18. Edlow JA, Kim S, Pelletier AJ, Camargo CA Jr. National study on emergency department visits for transient ischemic attack, 1992-2001. Acad Emerg Med. 2006;13(6):666-72. https://doi.org/10.1197/j.aem. 2006.01.014.

19. Bravata DM, Myers LJ, Cheng E, Reeves M, Baye F, Yu Z, Damush T, Miech EJ, Sico J, Phipps M, Zillich A, Johanning J, Chaturvedi S, Austin C, Ferguson J, Maryfield B, Snow K, Ofner S, Graham G, Rhude R, Williams LS, Arling G. Development and validation of electronic quality measures to assess care for patients with transient ischemic attack and minor ischemic stroke. Circ Cardiovasc Qual Outcomes. 2017;10(9). https://doi.org/10.1161/circoutcomes.116. 003157.

20. Damush TM, Miech EJ, Sico JJ, Phipps MS, Arling G, Ferguson J, Austin C, Myers L, Baye F, Luckhurst C, Keating AB, Moran E, Bravata DM. Barriers and facilitators to provide quality TIA care in the Veterans Healthcare Administration. Neurology. 2017;89(24):2422-30. https://doi.org/10.1212/wnl.0000000000004739.

21. Johnston SC, Nguyen-Huynh MN, Schwarz ME, Fuller K, Williams CE, Josephson SA, Hankey GJ, Hart RG, Levine SR, Biller J, Brown RD, Jr., Sacco RL, Kappelle LJ, Koudstaal PJ, Bogousslavsky J, Caplan LR, van Gijn J, Algra A, Rothwell PM, Adams HP, Albers GW. National Stroke Association guidelines for the management of transient ischemic attacks. Ann Neurol. 2006;60(3):301-13. https://doi.org/10. 1002/ana.20942.

22. Kernan WN, Ovbiagele B, Black HR, Bravata DM, Chimowitz MI, Ezekowitz MD, Fang MC, Fisher M, Furie KL, Heck DV, Johnston SC, Kasner SE, Kittner SJ, Mitchell PH, Rich MW, Richardson D, Schwamm LH, Wilson JA. Guidelines for the prevention of stroke in patients with stroke and transient ischemic attack: a guideline for healthcare professionals from the American Heart Association/ American Stroke Association. Stroke. 2014;45(7):2160-236. https://doi. org/10.1161/str.0000000000000024.

23. Meschia JF, Bushnell C, Boden-Albala B, Braun LT, Bravata DM, Chaturvedi S, Creager MA, Eckel RH, Elkind MS, Fornage M, Goldstein LB, Greenberg SM, Horvath SE, Iadecola C, Jauch EC, Moore WS, Wilson JA. Guidelines for the primary prevention of stroke: a statement for healthcare professionals from the American Heart Association/American Stroke Association. Stroke. 2014;45(12):3754832. https://doi.org/10.1161/str.0000000000000046.

24. Whisnant JP. Stroke: populations, cohorts, and clinical trials. Boston: Butterworth-Heinemann; 1993. 263 p.

25. Handbook of Neuroepidemiology. In: Alter PBGaM, editor. New York: Marcel Dekker, Inc; 1994. p. 83-98.

26. Asimos AW, Johnson AM, Rosamond WD, Price MF, Rose KM, Catellier D, Murphy CV, Singh S, Tegeler CH, Felix A. A multicenter evaluation of the ABCD2 score's accuracy for predicting early ischemic stroke in admitted patients with transient ischemic attack. Ann Emerg Med. 2010;55(2):201-10.e5. https://doi.org/10.1016/j.annemergmed. 2009.05.002.

27. Edwards D, Cohn SR, Mavaddat N, Virdee SK, Lasserson D, Milner S, Giles M, McManus R, Mant J. Varying uses of the ABCD2 scoring system in primary and secondary care: a qualitative study. BMJ Open. 2012;2(6). https://doi.org/10.1136/bmjopen-2012-001501.

28. Gattellari M, Goumas C, Garden F, Worthington JM. Relative survival after transient ischaemic attack: results from the Program of Research Informing Stroke Management (PRISM) study. Stroke. 2012;43(1):79-85. https://doi.org/10.1161/strokeaha.111.636233.

29. Yakhkind A, McTaggart RA, Jayaraman MV, Siket MS, Silver B, Yaghi S. Minor stroke and transient ischemic attack: research and practice. Front Neurol. 2016;7:86. https://doi.org/10.3389/fneur.2016.00086. 
30. Oostema JA, Brown MD, Reeves M. Emergency Department Management of Transient Ischemic Attack: a survey of emergency physicians. J Stroke Cerebrovasc Dis. 2016;25(6): 1517-23. https://doi.org/10.1016/j. jstrokecerebrovasdis.2016.02.028.

31. Furnham A. Response bias, social desirability and dissimulation Personal Individ Differ. 1986;7(3):385-400. https://doi.org/10.1016/ 0191-8869(86)90014-0.

32. Sanders LM, Srikanth VK, Jolley DJ, Sundararajan V, Psihogios H, Wong K, Ramsay D, Phan TG. Monash transient ischemic attack triaging treatment: safety of a transient ischemic attack mechanismbased outpatient model of care. Stroke. 2012;43(11):2936-41. https:// doi.org/10.1161/strokeaha.112.664060.

33. Ben-Yakov M, Kapral MK, Fang J, Li S, Vermeulen MJ, Schull MJ. The Association between emergency department crowding and the disposition of patients with transient ischemic attack or minor stroke.
Acad Emerg Med. 2015;22(10):1145-54. https://doi.org/10.1111/ acem. 12766.

34. Dutta D, Bailey SJ. Validation of ABCD2 scores ascertained by referring clinicians: a retrospective transient ischaemic attack clinic cohort study. Emerg Med J 2016;33(8):543-7. https://doi.org/10.1136/emermed2015-205519.

35. Li Q , Zhu X, Feng C, Fang M, Liu X. Duration of symptom and ABCD2 score as predictors of risk of early recurrent events after transient ischemic attack: a hospital-based case series study. Med Sci Monit. 2015;21:262-7. https://doi.org/10.12659/msm.892525.

36. McKesson InterQual Actionable Evidence-Based Criteria Portfolio United States Department of Veterans Affairs; 2014.; LOC: Acute Adult; Stroke/ TIA Subset. Available from: http://vaww.oqsv.med.va.gov/functions/ integrity/um/InterQualBookView2010-2017/umInterQualBookView. aspx. Date last accessed: October 10, 2018. 